\title{
Blood coagulation parameters in patients with severe COVID-19 from Kermanshah Province, Islamic Republic of Iran
}

\author{
Babak Sayad ${ }^{1}$ and Zohreh Rahimi ${ }^{2,3}$
}

${ }^{1}$ Infectious Diseases Research Center, Kermanshah University of Medical Sciences, Kermanshah, Islamic Republic of Iran. ${ }^{2}$ Fertility and Infertility Research Center, Health Technology Institute, Kermanshah University of Medical Sciences, Kermanshah, Islamic Republic of Iran. ${ }^{3}$ Department of Clinical Biochemistry, Kermanshah University of Medical Sciences, Kermanshah, Islamic Republic of Iran. (Correspondence to: Zohreh Rahimi: zrahimi@kums.ac.ir; rahimizus@yahoo.com).

\begin{abstract}
Background: Infection with coronavirus disease 2019 (COVID-19) could be complicated with coagulopathy and high risk of thromboembolic events.

Aims: The main aim of the present study was to find the coagulation profile of intensive care unit (ICU) admitted patients with COVID-19 from Kermanshah, Islamic Republic of Iran.

Methods: Coagulation parameters were analyzed using appropriate methods in 74 patients (24 patients aged <60 years and 50 patients $\geq 60$ years) and were compared with 35 survivors (severe COVID-19) and 39 non-survivors (severe COVID-19) historically admitted to the ICU.

Results: Forty-two percent of patients had abnormal prothrombin time and international normalized ratio. The rates of mortality and comorbidity in patients aged $\geq 60$ years were $73.7 \%$ and $78.4 \%$ compared to $26.3 \%$ and $21.6 \%$, respectively, in patients aged $<60$ years.

Conclusion: We found an abnormal pattern of coagulation parameters and association of advanced age and comorbidities with a high rate of mortality in severe COVID-19 patients, which should be taken into consideration in their hospital management.

Keywords: COVID-19, coagulation, prothrombin time, international normalized ratio, D-dimer, mortality

Citation: Sayad B; Rahimi Z. Blood coagulation parameters in patients with Severe COVID-19 from Kermanshah Province, Islamic Republic of Iran. East Mediterr Health J. 2020;26(9):999-1004. https://doi.org/10.26719/emhj.20.105

Received: 13/06/20; accepted: 20/07/20

Copyright @ World Health Organization (WHO) 2020. Open Access. Some rights reserved. This work is available under the CC BY-NC-SA 3.0 IGO license (https://creativecommons.org/licenses/by-nc-sa/3.o/igo)
\end{abstract}

\section{Introduction}

The severe acute respiratory syndrome coronavirus 2 (SARS-CoV-2) that is responsible for coronavirus disease 2019 (COVID-19) resulted in systemic inflammatory response and imbalance between homeostatic mechanisms of procoagulant and anticoagulant. Moreover, it is complicated with thrombotic complications (1). In response to COVID-19 infection, activation of $\mathrm{T}$ cells along with massive production and release of cytokines occur with subsequent damage to internal organs, and primarily the lungs (2). Around $40 \%$ of hospitalized patients with COVID-19 are at a high risk of development of venous thromboembolism (VTE) (3). Among non-intensive care unit (ICU) COVID-19 French patients receiving thromboprophylaxis, the incidence of VTE and pulmonary embolism were $22.5 \%$ and $10 \%$, respectively (4). Abnormal coagulation factors in Chinese patients with COVID-19 were associated with poor prognosis (5). In a number of studies (but not all) in-hospital death was associated with high level of D-dimer (> $1 \mu \mathrm{g} / \mathrm{ml}$ ) on admission (6).

There is an association between age and clinical severity of COVID-19 in patients aged $\geq 60$ years, who demonstrate heavier clinical manifestations, higher severity and longer disease courses compared to patients aged $<60$ years $(7)$. The rate of mortality among ICU- admitted patients with COVID-19 has been reported to be from $10 \%$ to around $44 \%$, varying according to age and the presence of comorbidities that resulted in multi-organ failure (8-11).

There is no available study related to the evaluation of coagulation parameters in COVID-19 patients from the Islamic Republic of Iran. Kermanshah Province in the west of the country borders Iraq and has extensive communication with the Iraqi Kurdistan region, which could be a challenge in disease control. More comparison of reports from various populations related to the clinical course, outcome of COVID-19 and blood coagulation profile in these patients are necessary to help the management and treatment of the disease.
Aims
The aims of the present study were to find the coagula- tion profile of 74 consecutive ICU-admitted patients with COVID-19 from Kermanshah Province, Islamic Republic of Iran, and to determine the influence of age and comor- bidities on the level of these parameters. In addition, we aimed to compare coagulation parameters between sur- vivors and non-survivors to detect their effects on the severity and outcome of the disease. 


\section{Methods}

We studied 74 consecutive patients with confirmed COVID-19 admitted to the ICU of Farabi Hospital of Kermanshah University of Medical Sciences, being the second referral centre of COVID-19 in Kermanshah Province, from 7 March to 12 May 12, 2020. Patients consisted of 44 males and 30 females with a mean age of $65.1 \pm 17.1$ years. There were 50 patients $(67.6 \%)$ aged 60 years or older and 24 patients $(32.4 \%)$ aged less than 60 years. Diagnosis of COVID-19 was made according to the chest CT scan and/ or real time PCR. The samples for coagulation tests were collected at hospital admission. The prothrombin time (PT), aPTT, fibrinogen, and international normalized ratio (INR) were measured using Coatron M2 coagulation analyzer (TECO Medical Instruments, Germany). D-dimer was measured by a Siemens device (Germany) using chemiluminescence method. Although our research was an observational study, verbal consent was obtained from patients or from next-of-kin.

A two-tailed student's t-test and ANOVA were used to compare quantitative data between groups. Using the $\chi^{2}$ test the categorical variables were compared between groups. The quantitative data were expressed as Mean \pm SD. P-value $<0.05$ was considered as statistically significant. SPSS statistical software package version 16.0 (SPSS Inc., Chicago, IL, USA) was used for statistical analysis.

\section{Ethics approval}

The Ethics Committee of Kermanshah University of Medical Sciences approved the study (Ethics code: IR. KUMS.REC.1399.044) and the study was in accordance with the principles of the Declaration of Helsinki II.

\section{Results}

Twenty-six out of 74 patients $(35.1 \%)$ required tracheal intubation (64.1\% non-survivors and $2.9 \%$ survivors, $P<$ 0.001). Fifty-one out of 74 patients (around 69\%) had comorbidities (hypertension, diabetes mellitus, coronary artery disease, cancer, renal transplantation, chronic obstructive pulmonary disease, and osteomyelitis). The overall rate of mortality was $52.7 \%$. The mean days of hospitalization were 10.8 days (1-39 days). Table 1 indicates the levels of coagulation factors measured at admission in studied patients. Lower platelet (PLT) count was detected among non-survivors compared to survivors; in addition, patients with comorbidities had lower PLT count than patients without comorbidities (Table 1). Two (one male and one female, 70 and 68 years old, respectively) out of three patients with PLT count $\leq 36 \times 10^{3} /$ $\mu \mathrm{L}$ died. Twenty-two patients (around 30\%), had thrombocytopenia (PLT $\left.<150 \times 10^{3} / \mu \mathrm{L}\right)$, of which 15 patients were aged 60 years or older and 7 patients less than 60 years old, including 16 patients with comorbidity (72.7\%) and 6 patients without comorbidity $(27.3 \%)(P=0.16)$.

The PT $=15.6 \pm 3.9(12.5-35.4) \mathrm{sec}$ in all patients and was longer in non-survivors than survivors (Table 1). Fortytwo percent of the patients ( 31 individuals) had abnormal $\mathrm{PT}$ and $\operatorname{INR}(>14.5 \mathrm{sec}$, and $>1.2$, respectively). There were 5 patients with a PT of 27-35 sec and an INR of 1.7-5.1 that all died except one. The only case with critical value of an INR of 5.1 was a 76-year-old female with a PT of 35.4 $\mathrm{sec}$, and a D-dimer of $15 \mu \mathrm{g} / \mathrm{ml}$ who required tracheal intubation but died after 6 days' hospitalization.

In addition, significantly higher PT and INR levels were observed in patients with comorbidity compared to those without (Table 1). Comparing patients demonstrating the concomitant presence of two comorbidities with those who lack comorbidity indicated a PT of $17.5 \pm 6.1$ vs.14.4 $\pm 1.64 \sec (P=0.045)$ and an INR of $1.8 \pm 1.1$ vs.1.22 $\pm 0.21(P=0.03)$. The mean level of $D$-dimer available from 16 patients was $5.1 \pm 7.3(0.1-25) \mu \mathrm{g} / \mathrm{ml}$, which was higher in non-survivors than survivors (Table 1). The aPTT and fibrinogen levels in all patients were 39.1 \pm 9.2 (25-68) sec and 3.37 \pm 1.80 (135-751) g/L, respectively (Table 1). The abnormal pattern of coagulation parameters (higher PT, aPTT, INR, and D-dimer) observed in 30 out of 39 patients $(77 \%)$ with comorbidities who died compared to 9 non-survived patients without comorbidities.

\begin{tabular}{|c|c|c|c|c|c|}
\hline Variable & $\begin{array}{c}\text { All patients }(n=74) \\
\text { Mean } \pm S D\end{array}$ & $\begin{array}{c}\text { Survivors } \\
(n=35) \\
\text { Mean } \pm S D\end{array}$ & $\begin{array}{c}\begin{array}{c}\text { Non-survivors } \\
(\boldsymbol{n}=39) \\
\text { Mean } \pm \mathrm{SD}, P\end{array}\end{array}$ & $\begin{array}{c}\text { Patients without } \\
\text { comorbidities } \\
(n=23) \\
\text { Mean } \pm \text { SD }\end{array}$ & $\begin{array}{c}\text { Patients with } \\
\text { comorbidities } \\
(n=51) \\
\text { Mean } \pm \text { SD }, P\end{array}$ \\
\hline Age (years) & $65.1 \pm 17.1(23-90)$ & $63.6 \pm 18.7$ & $66.5 \pm 15.5,0.48$ & $55.2 \pm 16$ & $69.4 \pm 15.8,0.001$ \\
\hline Sex (male/female) & $44 / 30$ & $21 / 14(47.7 / 46.7 \%)$ & $23 / 16(52.3 / 53.3 \%)$ & $17 / 6(38.6 / 20 \%)$ & $27 / 24(61.4 / 80 \%)$ \\
\hline PLT counts $\left(\times 10^{3} / \mu \mathrm{L}\right)$ & $207.8 \pm 111.5(13.5-707)$ & $223.9 \pm 124.1$ & $193 \pm 9.8,0.24$ & $218.7 \pm 117.7$ & $186.9 \pm 97.3,0.22$ \\
\hline PT (sec) & $15.6 \pm 3.9(12.5-35.4)$ & $15.1 \pm 2.8$ & $16 \pm 4.6,0.29$ & $14.4 \pm 1.6$ & $16.1 \pm 4.4,0.024$ \\
\hline aPTT (sec) & $39.1 \pm 9.2(25-68)$ & $39 \pm 10.5$ & $39.1 \pm 8.2,0.98$ & $38.2 \pm 11.2$ & $39.4 \pm 8.5,0.68$ \\
\hline INR & $1.42 \pm 0.62(1-5.1)$ & $1.4 \pm 0.47$ & $1.5 \pm 0.72,0.39$ & $1.22 \pm 0.22$ & $1.50 \pm 0.7,0.02$ \\
\hline D-dimer $(\mu \mathrm{g} / \mathrm{ml})$ & $\begin{array}{c}5.1 \pm 7.3(0.1-25) \\
n=16\end{array}$ & $4.8 \pm 9.9$ & $5.3 \pm 5.9,0.92$ & $5.1 \pm 7$ & $5.1 \pm 7.6,0.99$ \\
\hline Fibrinogen (g/L) & $\begin{array}{c}3.37 \pm 1.80(135-751) \\
n=16\end{array}$ & $3.38 \pm 2.39$ & $3.36 \pm 1.28,0.98$ & 2.69 & $3.45 \pm 1.9,0.71$ \\
\hline
\end{tabular}

PLT= platelet; PT = prothrombin time; aPTT =activated partial thromboplastin time;INR=international normalized ratio 
In Table 2 the coagulation parameters have been compared between two age groups: patients aged $\geq 60$ years old $(n=50)$ and those below 60 years old $(n=24)$. There were 50 patients $(68 \%)$ aged $60-90$ years $(75.4 \pm 8.5$ years) a PT of $16.1 \pm 4.4 \mathrm{sec}$ and an INR of $1.51 \pm 0.71$, which compared to 24 patients (32\%) aged below 60 years with a mean age of $44.2 \pm 8.9$ years and a PT level of $14.6 \pm 1.9 \mathrm{sec}$ $(P=0.059)$ and an INR of $1.26 \pm 0.29(P=0.056)$. Among patients $\geq 60$ years $80 \%$ needed a ventilator and $78.4 \%$ had comorbidities. The mortality rate was $73.7 \%$ compared to patients aged $<60$ years of whom $20 \%$ required a ventilator $(P=0.09), 21.6 \%(P=0.002)$ had comorbidities, and the death rate was $26.3 \%(P=0.2)$ (Table 2).

\section{Discussion}

The overall rate of mortality in severely affected patients in this study was $52.7 \%$. Patients were mostly aged 60 years or older with a high rate of comorbidity $(69 \%)$ and a mortality rate of $73.7 \%$. The high mortality rate among ICU-admitted patients from the present study was due increased age and a high rate of comorbidities. In a referral centre for COVID-19 in Tehran, the two-week mortality rate was $25 \%$ among 72 ICU-admitted patients with COVID-19. However, the age of these patients had not been reported (12). Three studies from Italy reported a difference in mortality rate; in one study the ICU and the hospital mortality rate of COVID-19 patients with a mean age of 61 years were $10 \%$ and $12.5 \%$, respectively (8). In a second study among patients with a mean age of 70 years the tracheal intubation rate was $8.5 \%$ and the overall mortality was $12.8 \%$. All patients who died were on ventilation and had multiple comorbidities. Alterations in coagulation parameters were observed in $41 \%$ of cases (10). In a third study $43.7 \%$ of ICU-admitted patients with a mean age of 61 years did not recover and died due to hypoxia and multi-organ failure (11).

However, in one study from the Netherlands the mortality rate among ICU-admitted patients was $22 \%$ (9). It was noted that in older adults immune senescence and enhanced inflammatory responses associated with aging might increase the risk of infection and dysregulation of immune response to SARS-CoV-2 (13,14); in addition, comorbidities increase with aging (13). In a study from Mexico, higher age was found to be a predictor of disease mortality, but comorbidities and determinants of structural health had a greater role in the severity of disease in older patents (13).

Thus, there is an age-based exponential increase in the mortality rate. Around $80 \%$ and $90 \%$ of deaths due to COVID-19 occurred in patients aged $>70$ years and $\geq 60$ years in Korea and Italy, respectively. In Korea the overall case fatality rate was $2.37 \%$, which was much higher in older patients (15).

Thrombocytopenia was detected in around $30 \%$ of mostly older patients with comorbidities and in nonsurvivors. The longer PT and higher INR was found in $42 \%$ of patients, especially in patients $>60$ years with increased comorbidities and mortality, compared to patients $<60$ years, also the PT $>27 \mathrm{sec}$ was fatal. Thrombocytopenia and abnormal coagulation parameters (PT, INR, D-dimer) could be considered as important indicators of severe COVID-19 associated with mortality. Using the cut-off value of D-dimer $1.5 \mu \mathrm{g} / \mathrm{mL}$ for prediction of VTE, 8 out of $16(50 \%)$ our patients had VTE. In a report from 81 severe COVID-19 ICU-admitted Chinese patients there were 20 (25\%) with VTE (16).

Various reports have been published regarding the levels of D-dimer and the severity of COVID-19. While in some studies in-hospital mortality was associated with a high level of D-dimer $(>1 \mu \mathrm{g} / \mathrm{ml})$ on admission, other studies found no significant difference in D-dimer level between severe and non-severe patients $(4,5,6)$. It should be considered that D-dimer assays are not necessarily comparable due to different calibrators, detection antibodies and methods (6). High levels of D-dimer have been associated with 28-day mortality among patients with infection or sepsis. The systemic pro-inflammatory cytokines contribute to plaque rupture through local inflammation, induced procoagulant pathway at multiple levels, such as induction of coagulation activation by proinflammatory cytokines of TNF, IL-1, IL-6 and IL12 , and haemodynamic alterations are mechanisms involved in predisposition to ischaemia and thrombosis (17). The most haemostatic abnormalities in patients with COVID-19 requiring greater mechanical ventilation, ICU admission, or death, were mild thrombocytopenia and increased levels of D-dimer, indicating the presence of some forms of coagulopathy with increased risk of thrombotic events (3).

Table 2 Coagulation parameters in patients with severe COVID-19 according to age

\begin{tabular}{|c|c|c|c|}
\hline Variable & $\begin{array}{c}\text { Less than } 60 \text { years }(n=24) \\
\text { Mean } \pm \text { SD }\end{array}$ & $\begin{array}{c}60 \text { years or more }(n=50) \\
\text { Mean } \pm \text { SD }\end{array}$ & $P$ value \\
\hline PLT counts $\left(\times 10^{3} / \mu \mathrm{L}\right)$ & $229 \pm 144.2$ & $196.9 \pm 92.2$ & 0.32 \\
\hline PT (sec) & $14.6 \pm 1.9$ & $16.1 \pm 4.4$ & 0.059 \\
\hline aPTT (sec) & $37.8 \pm 7.4$ & $39.6 \pm 10$ & 0.42 \\
\hline INR & $1.26 \pm 0.29$ & $1.5 \pm 0.71$ & 0.056 \\
\hline D-dimer $(\mu \mathrm{g} / \mathrm{ml})$ & $\begin{array}{c}7.65 \pm 9.5 \\
n=7\end{array}$ & $\begin{array}{c}3.2 \pm 4.7 \\
n=9\end{array}$ & 0.28 \\
\hline Fibrinogen $(\mathrm{g} / \mathrm{L})$ & $\begin{array}{l}4.9 \pm 1.90 \\
n=6\end{array}$ & $\begin{array}{c}2.4 \pm 0.6 \\
n=10\end{array}$ & 0.08 \\
\hline
\end{tabular}


No prolonged aPTT (more than $70 \mathrm{sec}$ ) was observed in patients for this study, which might explain the absence of disseminated intravascular coagulation (DIC) bleeding in patients. In some patients with COVID-19 there was an associated coagulopathy, but even in those patients with DIC, bleeding was not manifested since these abnormalities could be the result of a profound inflammatory response that did not result in bleeding (18).

In Caucasian patients with COVID-19 and extended thrombo-prophylaxis with low molecular weight heparins, overt DIC rarely developed. However, in those patients with COVID-19 who developed DIC, this complication appeared during a late stage of the disease. A term of pulmonary intravascular coagulopathy was suggested for bilateral pulmonary inflammation observed in COVID-19 patients to discern from DIC (19).

Based on recommendations from the International Society on Thrombosis and Haemostasis, patients with markedly increased D-dimer (three to four-fold increase), should be considered for hospital admission even in the absence of other symptoms. In addition, all hospitalized COVID-19 patients with this elevation should receive thromboprophylaxis or full therapeutic-intensity anticoagulation (20).

\section{Conclusion}

The overall mortality rate in patients with severe COVID-19 was $52.7 \%$. However, the rate of mortality was $73.7 \%$ in patients $\geq 60$ years compared to $26.3 \%$ in patients aged $<60$ years. This study indicated that ages $>60$ years were associated with high rate of comorbidities, abnormal level of coagulation parameters and poor prognosis. In addition, we detected a high rate of coagulopathy (42\%) in severely affected patients with COVID-19. Furthermore, severe COVID-19 patients had low levels of PLT, high PT and INR that were associated with poor prognosis. The abnormal pattern of coagulation parameters was highly associated with comorbidities and mortality. Coagulation tests such as PLT, PT, PTT, D-dimer, and fibrinogen should be performed at hospital admission stage in patients suspected or confirmed to have COVID-19 infection in order to provide useful prognostic information. These patients should be treated with pharmacologic VTE prophylaxis unless there were specific contra-indications.

\section{Acknowledgement}

We thank all patients involved in the study.

Funding: None.

Competing interests: None declared.

\section{Paramètres de coagulation sanguine chez des patients atteints de COVID-19 sévère dans la province de Kermanshah (République islamique d'Iran)}

\section{Résumé}

Contexte : L'infection par la COVID-19 peut être compliquée par une coagulopathie et un risque élevé d'événements thromboemboliques.

Objectifs : L'objectif principal de la présente étude était de déterminer le profil de coagulation des patients atteints de COVID-19 admis en soins intensifs à Kermanshah (République islamique d'Iran).

Méthodes: Les paramètres de coagulation ont été analysés chez 74 patients (24 patients âgés de moins de 60 ans et 50 patients âgés de 60 ans et plus) à l'aide de méthodes appropriées et ont été comparés aux paramètres de 35 survivants (COVID-19 sévère) et 39 non-survivants (COVID-19 sévère) qui avaient été admis en soins intensifs.

Résultats : Pour quarante-deux pour cent ( $42 \%$ ) des patients, le temps de prothrombine et le rapport normalisé international étaient anormaux. Les taux de mortalité et de comorbidité chez les patients âgés de 60 ans et plus étaient de $73,7 \%$ et $78,4 \%$, contre à $26,3 \%$ et $21,6 \%$, respectivement, chez les patients âgés de moins de 60 ans.

Conclusions : Nous avons trouvé un schéma anormal des paramètres de coagulation et une association entre un âge avancé et des comorbidités avec un taux de mortalité élevé chez les patients atteints de COVID-19 sévère, qui devraient être pris en compte dans leur prise en charge à l'hôpital. 


\section{متثابتات تخثر الدم لدى الحالات الوخيمة لمرضى كوفيد 19 - من مقاطعة كرمانشاه، جمهورية إيران الإسلامية} بابك سياد، زهرة رحيمي

الخلفية: يمكن أن تتفاقم العدوى بمرض الفيروس التاجي 1920 (كوفيد-19) في وجود اعتلال التخثر ويرتفع خطر حدوث الانسداد التجلطي. الأهداف: الهدف الرئيسي من هذا البحث هو الكشف عن مرتسم التخثر في المرضى بكوفيد-19 الذين أدخلوا في وحدة العناية المركزة من كرمانشاه

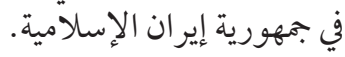

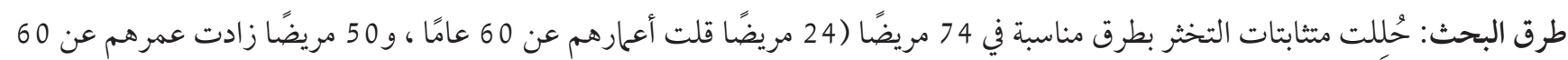

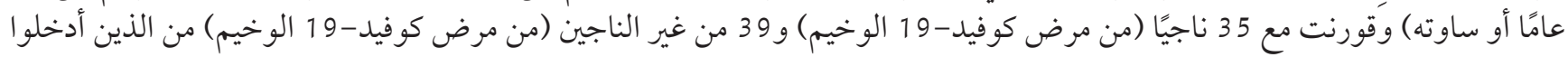

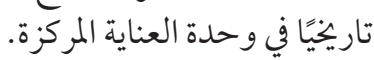
النتائج: كان اثنان وأربعون في المائة من المرضى لديهم مستوى غير طبيعي في زمن البروثرومبين و النسبة المعيارية الدولية. وكانت معدلات ألات الوفيات

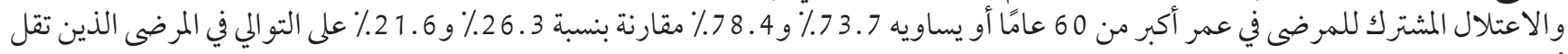
أعمارهم عن 60 عامًا.

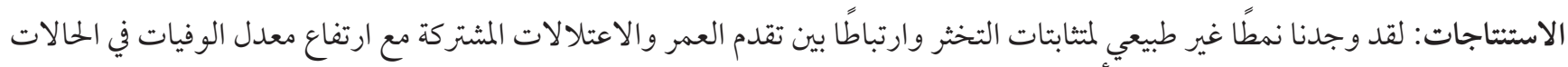

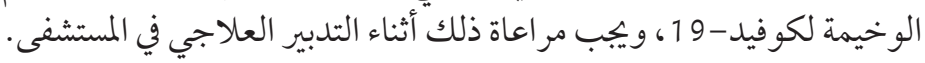

\section{References}

1. Giannis D, Ziogas IA, Gianni R. Coagulation disorders in coronavirus infected patients: COVID-19, SARS-CoV-1, MERS-CoV and lessons from the past. J Clin Virol. 2020;127:104362.

2. Ebrahimi A, Sayad B, Rahimi Z. COVID-19 and psoriasis: biologic treatment and challenges. J Dermatol Treat. 2020 doi:10.1080/09 546634.2020.1789051.

3. Bikdeli B, Madhavan MV, Jimenez D, Chuich T, Dreyfus I, Driggin E, et al. COVID-19 and thrombotic or thromboembolic disease: implications for prevention, antithrombotic therapy, and follow-up. J Am Coll Cardiol. 2020 Jun 16;75(23):2950-2973 doi:10.1016/j. jacc.2020.04.031.

4. Artifoni M, Danic G, Gautier G, Gicquel P, Boutoille D, Raffi F, et al. Systematic assessment of venous thromboembolism in COVID-19 patients receiving thromboprophylaxis: incidence and role of D-dimer as predictive factors. J Thromb Thrombolysis. 2020 Jul;50(1):211-216 doi:10.1007/s11239-020-02146-Z.

5. Tang N, Li D, Wang X, Sun Z. Abnormal coagulation parameters are associated with poor prognosis in patients with novel coronavirus pneumonia. J Thromb Haemost. 2020;18(4):844-847.

6. Favaloro EJ, Thachil J. Reporting of D-dimer data in COVID-19: some confusion and potential for misinformation. Clin Chem Lab Med. 2020;58(8):1191-1199.

7. Liu Y, Mao B, Liang S, Yang JW, Lu HW, Chai YH ,et al. Association between age and clinical characteristics and outcomes of COVID-19. Eur Respir J. 2020;55(5):2001112 doi:10.1183/13993003.01112-2020.

8. Pavoni V, Gianesello L, Pazzi M, Stera C, Meconi T, Frigieri FC. Evaluation of coagulation function by rotation thromboelastometry in critically ill patients with severe COVID-19 pneumonia. J Thromb Thrombolysis. 2020 Aug;50(2):281-286 doi:10.1007/ s11239-020-02130-7.

9. Klok FA, Kruip MJHA, van der Meer NJM, Arbous MS, Gommers D, Kant KM, Kaptein FHJ, et al. Confirmation of the high cumulative incidence of thrombotic complications in critically ill ICU patients with COVID-19: An updated analysis. Thromb Res. 2020;191:148-150.

10. Annunziata A, Imitazione P, Polistina GE. Pulmonary embolism in Covid-19. coagulation parameters, close monitoring to prevent? Turk Thorac J. 2020;21:287-288. doi:10.5152/TurkThoracJ.2020.20067

11. Ranucci M, Ballotta A, Di Dedda U, Bayshnikova E, Poli MD, Resta M, et al. The procoagulant pattern of patients with COVID-19 acute respiratory distress syndrome. J Thromb Haemost 2020;18(7):1747-1751

12. Jamaatia H, Dastana F, Tabarsic P, Marjanic M, Saffaeid A, Hashemiana MR. A fourteen-day experience with Coronavirus Disease 2019 (COVID-19) induced acute respiratory distress syndrome (ARDS): an Iranian treatment protocol. Iran J Pharma Res. 2020;19(1):31-36.

13. Bello-Chavolla OY, González-Díaz A, Antonio-Villa NE, Fermín-Martínez CA, Márquez-Salinas A, Vargas-Vázquez A, et al. Unequal impact of structural health determinants and comorbidity on COVID-19 severity and lethality in older Mexican adults: Considerations beyond chronological aging. J Gerontol Series A, glaa163, doi:10.1093/gerona/glaa163

14. Nikolich-Zugich J, Knox KS, Rios CT, Natt B, Bhattacharya D, Fain MJ. et al. SARS-CoV-2 and COVID-19 in older adults: what we may expect regarding pathogenesis, immune responses, and outcomes. GeroScience. 2020;42(2):505-514. 
15. Kang SJ, Jung SI. Age-related morbidity and mortality among patients with COVID-19. Infect Chemother. 2020;52(2):154-164.

16. Cui S, Chen S, Li X, Liu S, Wang F. Prevalence of venous thromboembolism in patients with severe novel coronavirus pneumonia. J Thromb Haemost. 2020;18:1421-1424

17. Zhou F, Yu T, Du R, Fan G, Liu Y, Liu Z, et al. Clinical course and risk factors for mortality of adult inpatients with COVID-19 in Wuhan, China: a retrospective cohort study. Lancet 2020; 395:1054-62.

18. Conners JM, Levy JH. COVID-19 and its implications for thrombosis and anticoagulation. Blood. 2020;135(23):2033-2040.

19. Fogarty H, Townsend L, Cheallaigh CN, Bergin C, Martin-Loeches I, Browne P, et al. COVID-19 coagulopathy in Caucasian patients. Br J Haematol. 2020;189:1044-1049.

20. Kollias A, Kyriakoulis KG, Dimakakos E, Poulakou G, Stergiou GS, Syrigos K. Thromboembolic risk and anticoagulant therapy in COVID-19 patients: Emerging evidence and call for action. Br J Haematol. 2020;189(5):846-847. 